Review began $02 / 26 / 2022$ Review ended 03/03/2022 Published 03/07/2022

() Copyright 2022

Abere et al. This is an open access article distributed under the terms of the Creative Commons Attribution License CC-BY 4.0 which permits unrestricted use, distribution, and reproduction in any medium, provided the original author and source are credited.

\section{Viral Hepatitis B and C: Knowledge Gaps and Patterns of Preventive Practices Among Medical Doctors in Rivers State, Nigeria

\author{
Sarah Abere ${ }^{1}$, Boma Oyan ${ }^{1}$, Dan-Jumbo Alali ${ }^{1}$, Hannah Omunakwe ${ }^{2}$, Mazpa Ejikem ${ }^{3}$
}

1. Internal Medicine, Rivers State University Teaching Hospital, Port-Harcourt, NGA 2. Haematology, Rivers State University Teaching Hospital, Port-Harcourt, NGA 3. Internal Medicine, University of Port-Harcourt Teaching Hospital, Port-Harcourt, NGA

Corresponding author: Sarah Abere, tamsabere@yahoo.com

\section{Abstract}

\section{Introduction}

Hepatitis B and C viruses can result in both acute and chronic hepatitis, ranging in severity from a mild acute disease to a serious, lifelong manifestation including liver cirrhosis and hepatocellular carcinoma. This study aims to determine the knowledge and attitudes of medical doctors in Rivers State, Nigeria, to hepatitis B and C as well as their practice for prevention and treatment of the same. We also assessed their practice of universal precaution, provision, and use of personal protective tools.

\section{Methods}

One hundred and fifty doctors in both the private and public sectors were interviewed using selfadministered questionnaires on viral hepatitis B and C. The questionnaire explored their knowledge and status of vaccination, viral hepatitis treatment, and their practice of universal safety precautions. Their responses were analyzed using SPSS version 21. Data was expressed in means and percentages.

\section{Results}

Out of all participants, $96 \%$ were aware that viral hepatitis B is preventable, while $46 \%$ erroneously believed that there is vaccination against the hepatitis $C$ virus. Only $50 \%$ of the respondents were aware of the availability of a cure for hepatitis $\mathrm{C}$ infection, and $16 \%$ of the participants knew about drugs used for its treatment. While $76 \%$ of the doctors had been vaccinated against hepatitis B virus, only $4 \%$ had received treatment after testing positive for hepatitis B. Furthermore, nearly all respondents admit practicing universal precaution, especially during venipuncture; however, protective measures such as disposable gloves were not readily available to $20 \%$ of our respondents. There was a statistically significant association between sex and duration of practice with knowledge of hepatitis B and C, as well as between practice type and vaccination status.

\section{Conclusion}

This study shows that knowledge of the treatment of viral hepatitis amongst healthcare practitioners such as doctors is poor, and although universal safety precautions are practiced, personal protective equipment is not readily available for use in our healthcare setting, placing healthcare workers at risk of infections. There is also a need to encourage vaccination amongst healthcare practitioners to protect them against contagious diseases like hepatitis B and C infections.

Categories: Internal Medicine, Gastroenterology, Infectious Disease

Keywords: universal precaution, personal protective equipment, hcv, hbv, viral hepatitis b and c, healthcare workers

\section{Introduction}

Hepatitis describes the inflammation of the liver. It could be caused by a variety of factors, including infections, alcohol, drugs, metabolic diseases, autoimmune disorders, etc. Viral hepatitis refers to the inflammation of the liver due to viral infections by one or more of the hepatitis viruses, including hepatitis A, B, C, D, or E viruses, and infrequently by cytomegalovirus, adenoviruses, Epstein-Barr virus, and herpes simplex virus. Viral hepatitis B and C (HBV and HCV, respectively) can cause acute infections, which may result in outcomes ranging from self-limiting hepatitis to liver fibrosis, cirrhosis, and hepatocellular carcinoma.

According to the World Health Organization (WHO), approximately 257 million people live with chronic HBV infection, 71 million people with chronic HCV infection globally, and an estimated 1.34 million people around the world died from viral hepatitis in 2015 , a number comparable to deaths caused by tuberculosis and higher than those caused by HIV [1].

In Africa, 60 million people and 11 million people live with hepatitis B and C [1]. The prevalence of viral hepatitis B and C in Nigeria is $11 \%$ and $2.2 \%$, respectively, with an average prevalence of HBV that ranges between 11- 13.7\%, with an estimation of 20 million Nigerians chronically infected [2]. The global epidemic 
of viral hepatitis is 10 times higher than that of HIV, and chronic viral hepatitis is now the second-largest killer infection after tuberculosis [3].

The hepatitis B virus (HBV) is a double-stranded DNA virus of the Hepadnaviridae family of viruses. The hepatitis $\mathrm{C}$ virus (HCV) is a single-stranded RNA virus of the Flaviviridae family. Humans are the only known natural host to hepatitis $\mathrm{B}$ and $\mathrm{C}$ viruses, and the viruses circulate in the blood in concentrations as high as 108 virions per ml. Transmission of HBV and HCV occurs through percutaneous or per mucosal exposure to infective body fluids, sexual contact, and drug injection; nosocomial transmission has also been documented $[4]$.

Many workers are frequently exposed to risk factors associated with their professional activities, and healthcare workers (HCWs) are not an exception. HCWs, especially doctors and nurses, represent a high-risk population for HBV and HCV infection. HBV is said to be the most infectious occupational hazard seen among HCWs [5]. Burzoni et al. reported that biological risk in the workplace is responsible for over 300,000 deaths per year worldwide [6]. This underlines the importance of increased awareness of the existence of these agents and the need for personal protection practices. Exposure to biological fluids such as urine, blood, and blood products, semen/vaginal fluids, and cerebrospinal fluids are sources of contamination, especially for viral infections [7]. Many HCWs in the course of their duties are exposed to hepatitis B and C infection through percutaneous transmission following a needle stick injury or cuts with infected sharp objects.

The knowledge and awareness of viral hepatitis in healthcare practitioners varies according to their level of education [8]. Mehriban et al. reported that $67.3 \%$ of the HCWs had an adequate level of knowledge on hepatitis B, but only half of them (49.3\%) had a good level of preventive practices [5]. It has been observed that healthcare workers have inadequate knowledge of how to protect themselves from blood-borne diseases, and this inadequacy could lead to low adherence to safety measures among them.

Lack of awareness of HBV and HCV modes of transmission, prevention, and treatment would probably contribute to the continuing transmission, exposure, and subsequent infection of HCWs, as well as missed opportunities for prevention (including vaccination) and treatment of infected persons.

In a knowledge and awareness survey of the American National Strategy for Prevention and Control of HBV and HCV, it was concluded that the knowledge about chronic HBV and HCV among HCWs was generally poor and insufficient [9]. Furthermore, a study conducted in 2009 among 1,362 Chinese non-specialist physicians on the knowledge of HCV infection reported that the respondents had little understanding of HCV infection, which might hamper their care of HCV patients [10]. In addition, despite the increased risk of exposure to biological agents faced by HCWs, knowledge and self-reported compliance to recommended personal protective equipment (PPE) use among clinicians remains suboptimal [11].

Therefore, we sought to assess the knowledge of hepatitis B and C virus, including their transmission, prevention, post-exposure prophylaxis, and treatment among medical doctors, a subset of healthcare workers in Rivers State, and furthermore to evaluate the percentage of doctors that have been vaccinated against viral hepatitis B and those who have been previously exposed and/or treated for viral hepatitis. Also, we sought to assess the attitudes and compliance to basic universal standard precaution guidelines for personal protection of this subset of healthcare providers in the state.

\section{Materials And Methods \\ Study design}

Rivers State is one of the thirty-six states of Nigeria, located in the southernmost part of the country. There are five tertiary and fifty-four secondary coded healthcare facilities in the state [12]. This study was a descriptive, cross-sectional study conducted among medical doctors in Rivers State, Nigeria.

\section{Sampling methodology}

Of the five tertiary health facilities, two of them were specialized hospitals for neuropsychiatry and dental/maxillofacial conditions, and the third (Niger Foundation Hospital) was temporarily closed and were all excluded from the study. The remaining two tertiary hospitals were then chosen, including the University of Port-Harcourt Teaching Hospital and Rivers State University Teaching Hospital. Out of the fifty-four secondary health facilities, ten hospitals were chosen by convenience sampling methodology, and questionnaires (see appendix) were distributed among 150 medical doctors in these facilities over four months.

\section{Data collection}

Data was collected using a structured, self-administered questionnaire. Fully informed and appropriate consent of the participants was sought and obtained. Demographics, including age, gender, years of practice, and private or public practice types, were assessed. Also, the questionnaire explored the knowledge of the participants on transmission, prevention, and drug treatment of hepatitis B and C, as well as their personal vaccination and treatment history on hepatitis B and C. Each correct response to the knowledge questions was scored one mark, and any wrong or non-response was scored zero. The total score obtained by each respondent was converted to a percentage and graded as poor (<50\%), fair $(50-74 \%)$, and good $(\geqslant 75 \%)$ 


\section{Cureus}

\section{Data analysis}

Data was assessed using a Statistical Package for Social Sciences (SPSS) version 21 (IBM Inc., Armonk, USA). Data was expressed as frequencies in percentages. Continuous variables were compared with the Student's ttest, while categorical parameters were compared with a chi-squared test. A p-value of $\leqslant 0.05$ was considered statistically significant.

\section{Ethics}

Ethical approval for the study was obtained from Rivers State University Teaching Hospital Ethics Committee (number: RSUTH/REC/2022153). Informed consent was sought and obtained from respondents before administering a questionnaire.

\section{Results}

\section{Socio-demographic characteristics}

A total of one hundred and fifty (150) doctors were assessed via structured questionnaires over a four-month period. The male to female ratio was 1.08 . The modal group for years of practice was $0-10$ years and 132 $(88 \%)$ of the respondents work in a public/government facility while $18(12 \%)$ were working in private facilities. (Table 1).

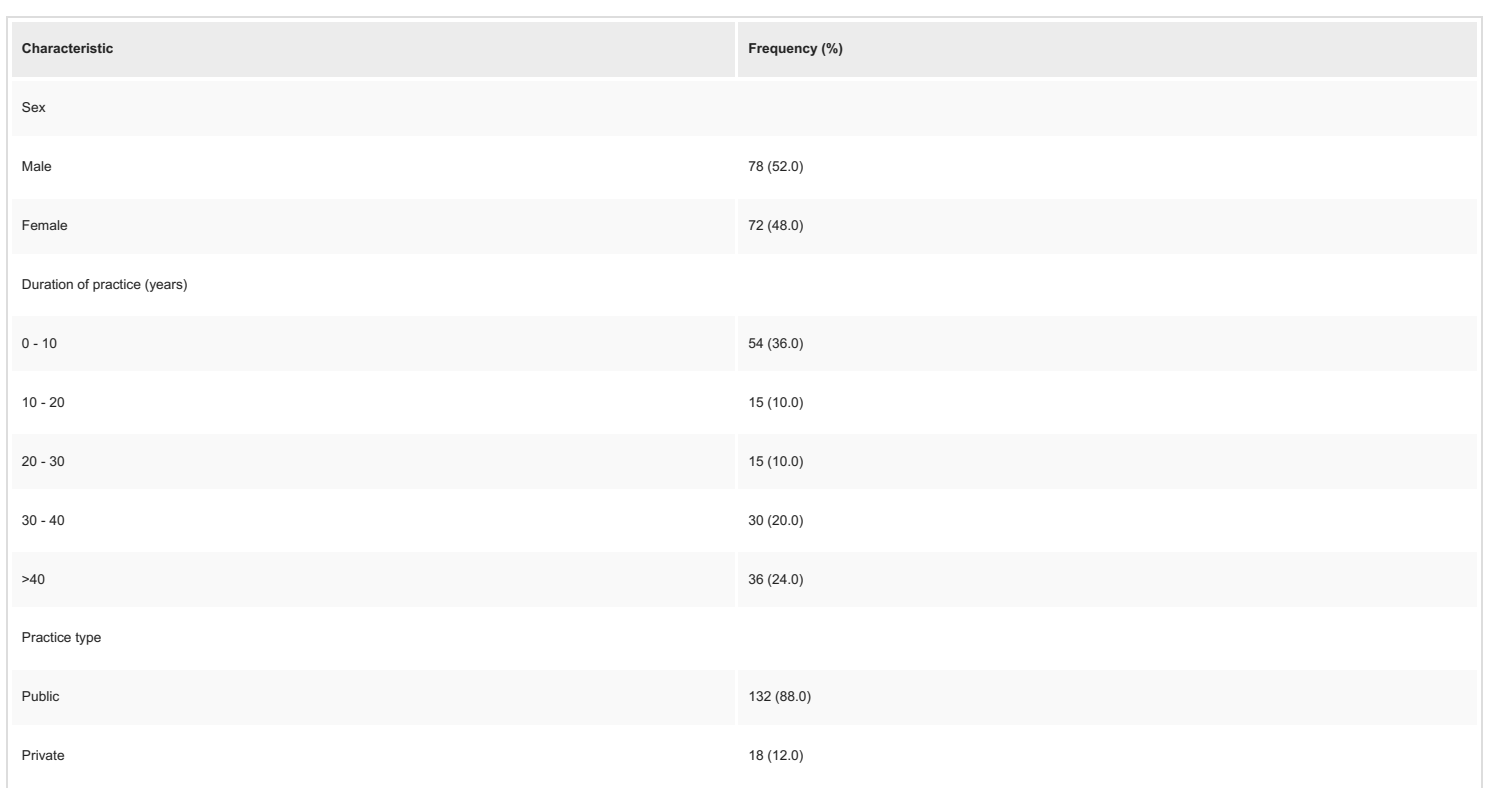

TABLE 1: Socio-demographic characteristics of the study population $(n=150)$

Knowledge of prevention, curability and mode of transmission

None of the respondents were found to have good knowledge, with $44 \%$ of doctors having fair knowledge and more than half of the doctors (56\%) showing poor knowledge on hepatitis B and C (Figure 1 ). 


\section{Cureus}

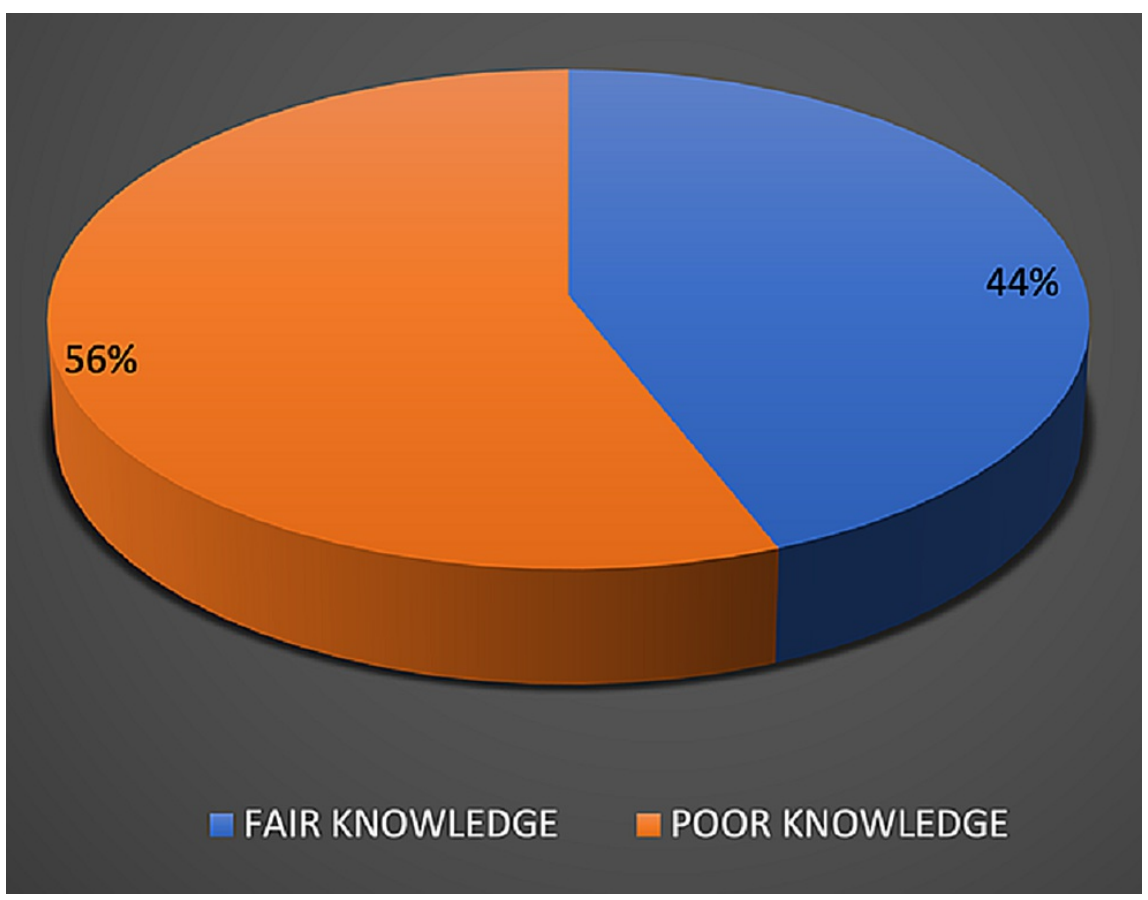

\section{FIGURE 1: Knowledge scores on hepatitis B and C in the study}

population

As shown in Table 2, a large majority (96\%) of the doctors assessed believed that HBV infection is preventable by vaccination while $46.0 \%$ believed HCV infection is preventable by vaccination. While $42 \%$ believed HBV infection can be cured, half of the respondents believed there was no cure for HCV infection. Concerning modes of transmission of both HBV and HCV, $84 \%$ of the respondents knew that vertical transmission occurred with HBV while $36 \%$ knew same for HCV. Also, $96 \%$ of respondents believed that HBV is transmissible by needle prick injury/blood products while $46.6 \%$ of respondents were aware that HCV is transmissible by needle prick injury/blood products. Most of the respondents (78\%) were aware of post exposure prophylaxis for viral hepatitis, and $86 \%$ of the respondents were aware of booster vaccination for HBV. However, majority of respondents were not aware of the drug treatments for HCV, including ledipasvir (94\%), simeprevir (94\%), daclatasvir (92\%), with ribavirin (26\%) and interferon (36\%) being the drugs for treatment of HCV most known to the respondents. Interferon (68\%) and lamivudine (54\%) were the drugs most known to be useful for treating HBV; however, $78 \%$ and $92 \%$ of respondents were not aware of the use of tenofovir and entecavir, respectively, for the treatment of HBV infection (Table 2). 


\section{Cureus}

\begin{tabular}{|c|c|c|}
\hline Variable & Yes $(\%)$ & No $\%$ \\
\hline HBV is prevennable by vaccination & $144(96.0)$ & $6(4.0)$ \\
\hline HCV is preventable by vaccination & $69(44.0)$ & $81(54.0)$ \\
\hline HBV is curable & $63(42.0)$ & $87(58.0)$ \\
\hline HCV is curable & $75(50.0)$ & $75(50.0)$ \\
\hline \multicolumn{3}{|l|}{ Commoner virus } \\
\hline HBV & $144(96.0)$ & \\
\hline HCV & $6(4.0)$ & \\
\hline \multicolumn{3}{|l|}{ Knowledge of modes of transmission of HBV } \\
\hline Needle-prick injury & $144(96.0)$ & $6(4.0)$ \\
\hline Vertical transmission & $126(84.0)$ & $24(16.0)$ \\
\hline Pleural fluids & $108(72.0)$ & $42(28.0)$ \\
\hline Urine & $81(54.0)$ & $69(46.0)$ \\
\hline Amniotic fluid & $90(60.0)$ & $60(40.0)$ \\
\hline \multicolumn{3}{|l|}{ Knowledge of modes of transmission of HCV } \\
\hline Needle-prick injury & $69(44.0)$ & $81(54.0)$ \\
\hline Vertical transmission & $54(36.0)$ & $96(54.0)$ \\
\hline Pleural fluids & $36(24.0)$ & $114(76.0)$ \\
\hline Urine & $30(20.0)$ & $120(80.0)$ \\
\hline Amniotic fluid & $45(30.0)$ & $105(70.0)$ \\
\hline \multicolumn{3}{|l|}{ Knowledge of drug treatment for viral hepatitis } \\
\hline Awareness of post-exposure prophylaxis & $117(78.0)$ & $33(22.0)$ \\
\hline Awareness of booster vaccination for $\mathrm{HBV}$ & $129(86.0)$ & $21(14.0)$ \\
\hline Lamivudine for HBV & $81(54.0)$ & $69(46.0)$ \\
\hline Interferon for HBV & $102(68.0)$ & $48(32.0)$ \\
\hline Tenofovir for HBV & $33(22.0)$ & $117(78.0)$ \\
\hline Entecavir for HBV & $12(8.0)$ & $138(92.0)$ \\
\hline Ribavirin for HBV & $42(28.0)$ & $108(72.0)$ \\
\hline Ledipasvir for HCV & $9(6.0)$ & $141(94.0)$ \\
\hline Simeprevir for HCV & $9(6.0)$ & $141(94.0)$ \\
\hline Daclatasvir for $\mathrm{HCV}$ & $12(8.0)$ & $138(92.0)$ \\
\hline Ribavirin for HCV & $39(26.0)$ & $111(74.0)$ \\
\hline Interferon for $\mathrm{HCV}$ & $54(36.0)$ & $96(64.0)$ \\
\hline Sofossbuvir for HCV & $24(16.0)$ & $126(84.0)$ \\
\hline
\end{tabular}

TABLE 2: Knowledge on viral hepatitis $B$ and $C$ in the study population $(n=150)$

HBV - hepatitis B virus; HCV - hepatitis C virus

There was a significant association between knowledge scores and the sex and duration of practice of the respondents with males having higher knowledge scores $(\mathrm{p}=0.011)$ and doctors with a duration of practice between 0 and 10 years reporting higher knowledge scores ( $\mathrm{p}=0.003$; Table 3 ). 


\section{Cureus}

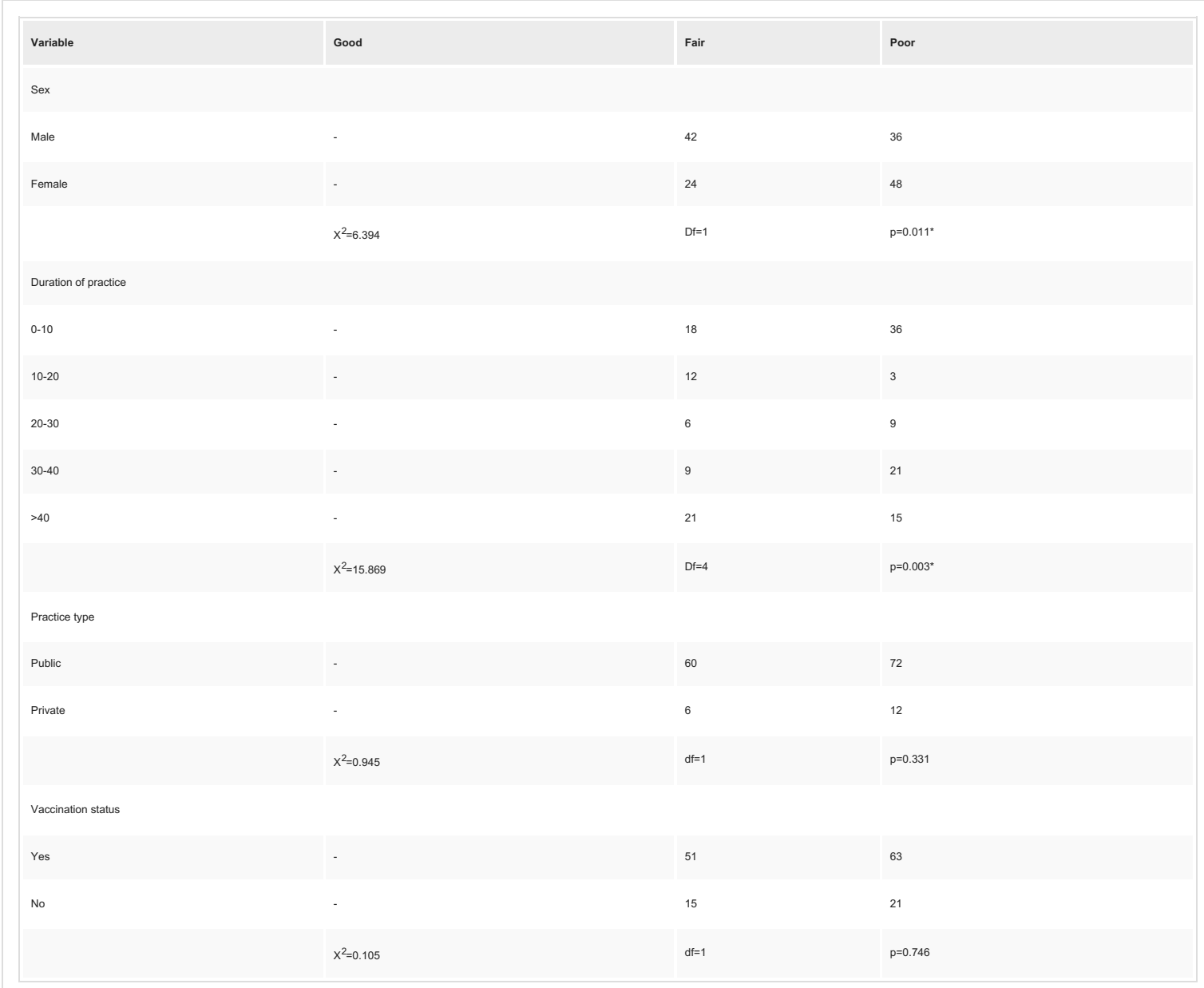

TABLE 3: Association between socio-demographic characteristics with knowlege on hepatitis $B$ and $C(n=150)$

* Significant p-value

Pattern of prevention and management practices of viral hepatitis $B$ and C

As shown in Table 4, 76\% of the doctors had been vaccinated against the hepatitis B virus. While all the respondents used hand gloves during venepuncture and sample collection, only $80 \%$ of the respondents used gloves during physical examination, and $94 \%$ had gloves available at their practice centre. Only $64 \%$ of respondents always practiced handwashing before and after procedures. While no respondent had been treated for HCV infection, six (4\%) of them had been diagnosed with HBV infection and had all received treatment for HBV infection. Nearly three-quarters (74\%) and $34 \%$ of the respondents had been involved in the treatment of a patients with HBV and HCV infection, respectively. 


\section{Cureus}

\begin{tabular}{|c|c|c|}
\hline Variable & Yes (\%) & No (\%) \\
\hline Have you been vaccinated for HBV? & $144(76.0)$ & $36(24.0)$ \\
\hline Are gloves available at your centre? & $141(94.0)$ & $9(6.0)$ \\
\hline Use of gloves during physical examination & $120(80.0)$ & $30(20.0)$ \\
\hline Use of gloves for venepuncture and sample collection & $150(100.0)$ & $0(0.0)$ \\
\hline \multicolumn{3}{|l|}{ Practice of handwashing pre and post procedures } \\
\hline Sometimes & $54(36.0)$ & \\
\hline Always & $96(64.0)$ & - \\
\hline \multicolumn{3}{|l|}{ Previous treatment } \\
\hline HBV & $6(4.0)$ & $144(96.0)$ \\
\hline HCV & $0(0.0)$ & $150(100.0)$ \\
\hline \multicolumn{3}{|l|}{ Treated patients } \\
\hline HBV & $111(74.0)$ & $39(26.0)$ \\
\hline $\mathrm{HCV}$ & $51(34.0)$ & 99 \\
\hline
\end{tabular}

TABLE 4: Pattern of prevention and management practices of viral hepatitis $B$ and $C$ in the study population $(n=150)$

HBV - hepatitis B virus; $\mathrm{HCV}$ - hepatitis $\mathrm{C}$ virus

A significant association was noted between the type of practice and the HBV vaccination status, with those in public practice being more vaccinated than those in private practice (Table 5). This association may be attributable to better access to vaccines in public hospitals. 


\section{Cureus}

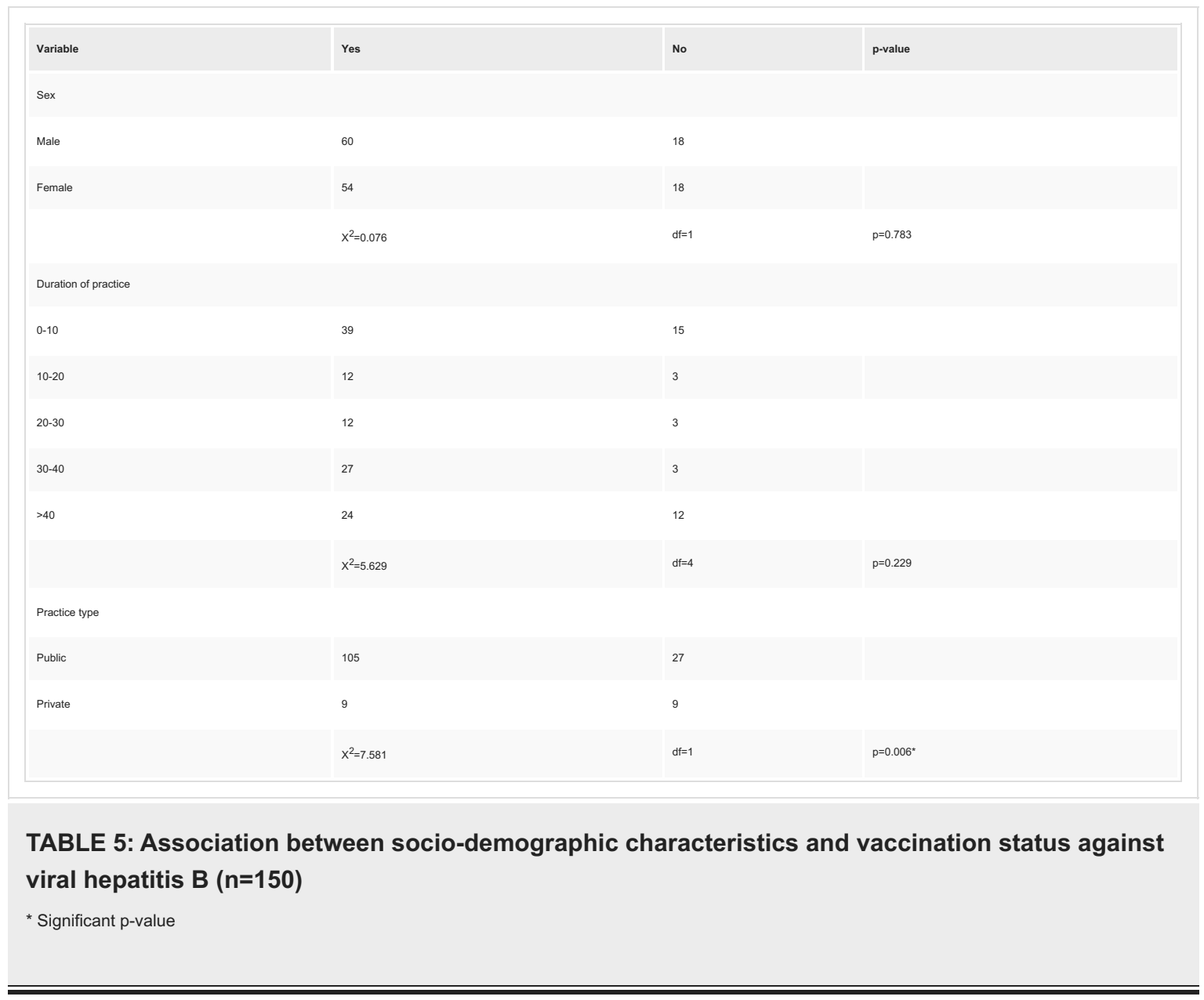

\section{Discussion}

This study aimed to assess the knowledge of HBV and HCV among doctors working in both private and public healthcare settings in Rivers State, Nigeria, in several domains, including transmission, prevention, prophylaxis, and treatment modalities. Vaccination status, exposure, and treatment for viral hepatitis were also evaluated, as well as compliance and challenges to the practice of universal, standard precautions for personal protection.

The high level of awareness for vaccination against HBV (96\%) was seen among the respondents in this study is similar to that reported in several other studies that reported awareness rates as high as $87 \%, 92 \%$, and $96 \%$, respectively [14-16].

Our study reported a low rate of knowledge (46.6\%) of the routes of transmission of HCV. This corresponds with findings in a study on the knowledge and attitude of healthcare workers towards HCV, where deficiencies range from $48 \%$ to $68 \%$ [17].

In our study, males reported a significantly higher proportion of respondents with better knowledge of hepatitis $\mathrm{B}$ and $\mathrm{C}$ as compared to females. This contrasts with previous studies which report better knowledge levels among females on hepatitis B [18] and C $[19,20]$.

It is imperative to note that misinformation about HBV transmission and treatment among doctors, as observed in this study, may create obstacles against prevention and treatment. Only $42 \%$ of our respondents were aware of close household contacts as an established high-risk source of transmission of HBV, necessitating screening as the risk of chronic infection after exposure to HBV is highest in early life. A crosssectional survey conducted among 217 members of the New Jersey Academy of Family Physicians similarly reported that only $50 \%$ of survey participants recommended screening household contacts of persons who had chronic HBV infection - an established high-risk population [21].

The majority of our respondents (76\%) have been vaccinated against HBV, and $86 \%$ of them were aware of the need for a booster dose. In addition, the knowledge on post-exposure prophylaxis was significantly different among participants based on the duration of practice.

Fewer doctors (34\%) have been involved in the management of HCV patients despite the rising prevalence of HCV in our environment, and this may be explained by a dearth in the knowledge of the recent drugs available for its treatment; $\leqslant 16 \%$ of the participants were aware of the direct-acting antivirals for HCV 
treatment. This highlights the need for continuous medical training of doctors, especially with the constantly changing landscape of HCV treatment.

Few doctors reported awareness of tenofovir, a cheap, effective, and readily available nucleoside analog, as a drug treatment for HBV and this low awareness was significantly higher among older practitioners. Only 12 of the respondents were aware of the drug entecavir - another effective nucleoside for HBV therapy. Considering the high prevalence of HBV in Nigeria, low knowledge of HBV treatment among doctors could negatively impact the drive towards the elimination of viral hepatitis by 2030 [22] and the sustainable development goal of increasing treatment for viral hepatitis from $1 \%$ to $80 \%$ by the year 2030 [23].

It is important to note that only about half (54\%) and two-thirds (68.0\%) of the participants were aware of lamivudine and interferon as drugs used for HBV treatment. The knowledge on lamivudine, tenofovir, entecavir, and ribavirin was significantly correlated with the duration of practice among the respondents, while no significant association was found between duration of practice and knowledge on interferon as drug treatment for HBV.

From our study, interferon was the only HCV drug known to a substantial proportion of our respondents (33.3\%), closely followed by ribavirin (22.2\%), which did not seem to depend on years of practice. However, there is low knowledge of newer and better drugs available for HCV, which reflects a need for continued training of non-gastroenterology doctors to manage viral hepatitis patients. Dublin et al. reported a similar knowledge gap in HCV treatment and curability among primary care providers compared to GI specialists [24]. A survey of 1,412 primary care providers in the United States that assessed knowledge about risk factors for HCV infection and management of hepatitis $\mathrm{C}$ reported that $27 \%$ of their respondents did not know which therapy to use after a patient is diagnosed HCV positive [24]. Furthermore, doctors who had practiced for more than 30 years had lower knowledge of newer HCV treatment drugs, which is similar to findings reported by Shehab et al. $[25,26]$.

Nearly half of the respondents in this study erroneously believed there is a curative treatment for HBV, and this corresponds with findings of a study conducted by Wu et al., which reported that $46 \%$ of their study population incorrectly responded that chronic HBV infection is curable [27]. This further supports the need for continued medical education of healthcare providers involved in viral hepatitis care.

Our study was limited by the relatively low number of respondents who participated in the study. Also, our study should have been carried out over a longer duration and should have a pre- and post-training component which could have assessed the knowledge of the participants better.

\section{Conclusions}

There is a high prevalence of viral hepatitis B and C in Africa. Our study, however, showed that knowledge about viral hepatitis B and C amongst medical doctors practicing in Rivers State, a highly populated Nigerian state, remains poor, especially in the domains of prevention and drug treatment for hepatitis B and $\mathrm{C}$. There is, however, relatively good knowledge on universal safety precautions. Knowledge scores were found to be significantly correlated with the respondents' sex, duration of practice, as well as type of practice. While a large majority of medical doctors had access to personal protective equipment, there was a limited practice of universal safety precautions among them. There is also a need to encourage vaccination amongst doctors to prevent HBV infection.

\section{Appendices \\ Questionnaire}

Introduction

My name is Dr. Sarah Abere and I lead a team of medical researchers to conduct a study titled: "Viral Hepatitides B and C: Knowledge Gaps and Patterns of Preventive Practices Among Medical Doctors in Rivers State". We will be interviewing medical doctors in Rivers State using this questionnaire. The objective of this study is to determine the knowledge and preventive practices of medical doctors on hepatitis B and C.

Confidentiality and Consent

During this study, you will be asked questions and your responses are going to be completely confidential and will not be used for any other purpose other than the above study. Your name is not going to be written on this form and thus, will not be used in connection with the information you provide. Please do NOT write your name. You are hereby informed that you do not have to answer any questions that you do not want to answer. However, we will appreciate your honest and appropriate answers in response to this study. There is no risk associated with your involvement in this study.

Your participation in this research will only require about 5 minutes of your time. Only numbers will be given to all completed questionnaires and names will not be recorded. Finally, your participation in this research is entirely voluntary.

Statement of Consent 


\section{Cureus}

I have read the description of this research and I understand it. I also understand that my participation is voluntary. I know enough about its objectives, methods, risk and benefits of the research study and I ascertain that I want to participate in it. I am duly informed that I may choose to stop responding to the questionnaire at any time I feel so.

Signature of participant/date : 


\section{Cureus}

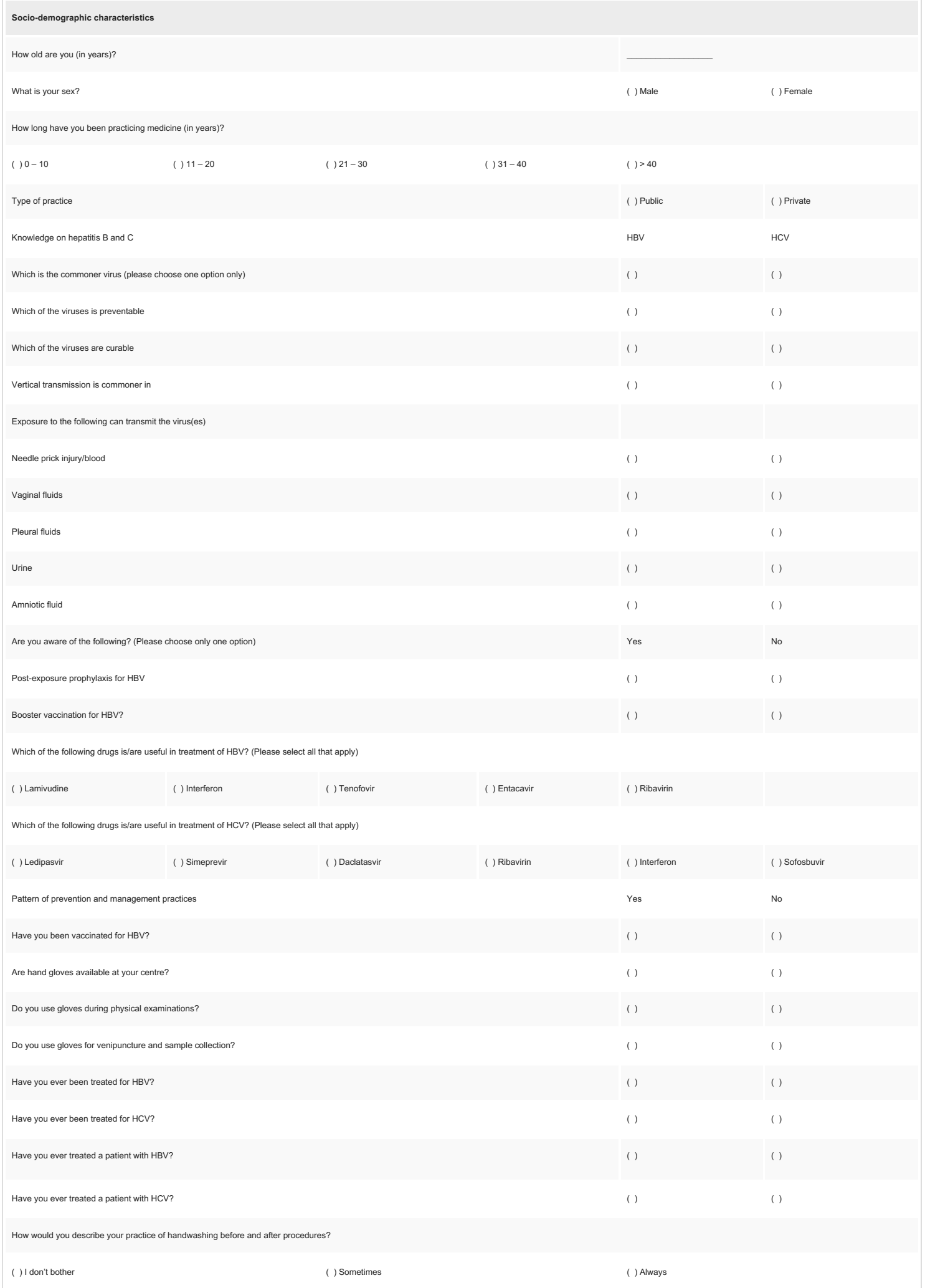

TABLE 6: Questionnaire on viral hepatitides B and C - knowledge gaps and patterns of preventive practices among medical doctors in Rivers State

HBV - hepatitis B virus; HCV - hepatitis C virus 


\section{Disclosures}

Human subjects: Consent was obtained or waived by all participants in this study. Rivers State University Teaching Hospital Research Ethics Committee issued approval RSUTH/REC/2022153. Animal subjects: All authors have confirmed that this study did not involve animal subjects or tissue. Conflicts of interest: In compliance with the ICMJE uniform disclosure form, all authors declare the following: Payment/services info: All authors have declared that no financial support was received from any organization for the submitted work. Financial relationships: All authors have declared that they have no financial relationships at present or within the previous three years with any organizations that might have an interest in the submitted work. Other relationships: All authors have declared that there are no other relationships or activities that could appear to have influenced the submitted work.

\section{References}

1. Global hepatitis report, 2017. (2017). Accessed: March 3, 2022: https://www.who.int/publications-detailredirect/global-hepatitis-report-2017.

2. National guidelines for the prevention, treatment and care of viral hepatitis in Nigeria . Federal Ministry of Health, Abuja, Nigeria; 2016. https://www.hepb.org/assets/Uploads/Nigeria-Hepatitis-Guidelines-TXguidelines.pdf

3. Hepatitis in the Western Pacific . (2020). Accessed: December 9, 2021: https://www.who.int/westernpacific/health-topics/hepatitis.

4. Rawat S, Sharma N, Kumar M, et al.: Quantification of HBV DNA and its impact on viral load monitoring . J Biomed Pharm Res. 2013, 2:75-80.

5. Mehriban N, Ahsan GU, Islam T: Knowledge and preventive practices regarding Hepatitis B among nurses in some selected hospitals of Dhaka city, Bangladesh. South East Asia J Public Health. 2014, 4:48-52. 10.3329/seajph.v4i1.21840

6. Burzoni S, Duquenne P, Mater G, Ferrari L: Workplace biological risk assessment: review of existing and description of a comprehensive approach. Atmosphere. 2020, 11:741. 10.3390/atmos11070741

7. Tarantola A, Abiteboul D, Rachline A: Infection risks following accidental exposure to blood or body fluids in health care workers: a review of pathogens transmitted in published cases. Am J Infect Control. 2006, 34:367-75. 10.1016/j.ajic.2004.11.011

8. Sari SYI, Ibrahim K, Haroen H, et al.: Knowledge, attitude and perceived adherence with universal precaution among health care workers in the obstetrics and gynaecology department of an Indonesian teaching hospital. Int J Infect Control. 2011, 7:1-4. 10.3396/ijic.V7i4.036.11

9. Institute of Medicine (US) Committee on the Prevention and Control of Viral Hepatitis Infection: Hepatitis and liver cancer: a national strategy for prevention and control of hepatitis. Colvin HM, Mitchell AE (ed): National Academies Press, Washington, USA; 2010. 10.17226/12793

10. Feng B, Zhang J, Wei L: Inadequate awareness of hepatitis C among nonspecialist physicians in China . Adv Med Educ Pract. 2011, 2:209-14. 10.2147/AMEP.S23887

11. Hu X, Zhang Z, Li N, et al.: Self-reported use of personal protective equipment among Chinese critical care clinicians during 2009 H1N1 influenza pandemic. PLoS One. 2012, 7 :e44723. 10.1371/journal.pone.0044723

12. Procurement list of coded health facilities in Rivers State . (2017). Accessed: February 6, 2022: http://ibrary.procurementmonitor.org/backend/files/List\%20of\%20Coded\%20Health\%20Facilities\%20in\%20RIVERS\%20STAT

13. Abiola AH, Agunbiade AB, Badmos KB, Lesi AO, Lawal AO, Alli QO: Prevalence of HBsAg, knowledge, and vaccination practice against viral hepatitis $B$ infection among doctors and nurses in a secondary health care facility in Lagos state, South-western Nigeria. Pan Afr Med J. 2016, 23:160. 10.11604/pamj.2016.23.160.8710

14. Kesieme EB, Uwakwe K, Irekpita E, Dongo A, Bwala KJ, Alegbeleye BJ: Knowledge of hepatitis B vaccine among operating room personnel in Nigeria and their vaccination status. Hepat Res Treat. 2011, 2011:157089. 10.1155/2011/157089

15. Okeke EN, Ladep NG, Agaba EI, Malu AO: Hepatitis B vaccination status and needle stick injuries among medical students in a Nigerian university. Niger J Med. 2008, 17:330-2. 10.4314/njm.v17i3.37404

16. Adekanle O, Ndububa DA, Olowookere SA, Ijarotimi O, Ijadunola KT: Knowledge of hepatitis B virus infection, immunization with hepatitis B vaccine, risk perception, and challenges to control hepatitis among hospital workers in a Nigerian tertiary hospital. Hepat Res Treat. 2015, 2015:439867. $10.1155 / 2015 / 439867$

17. Korkmaz P, Uyar C, Ozmen A, Toka O: Knowledge and attitude of health care workers toward patients with hepatitis C infection. Southeast Asian J Trop Med Public Health. 2016, 47:935-44.

18. Mansour-Ghanaei R, Joukar F, Souti F, Atrkar-Roushan Z: Knowledge and attitude of medical science students toward hepatitis B and C infections. Int J Clin Exp Med. 2013, 6:197-205.

19. Khan N, Ahmed SM, Khalid MM, Siddiqui SH, Merchant AA: Effect of gender and age on the knowledge, attitude and practice regarding hepatitis B and C and vaccination status of hepatitis B among medical students of Karachi, Pakistan. J Pak Med Assoc. 2010, 60:450-5.

20. Ahmad A, Munn Sann L, Abdul Rahman H: Factors associated with knowledge, attitude and practice related to hepatitis B and C among international students of Universiti Putra Malaysia. BMC Public Health. 2016, 16:611. 10.1186/s12889-016-3188-5

21. Screening for Chronic Hepatitis B Among Asian/Pacific Islander Populations - New York City, 2005 . (2006). Accessed: Deceber 10, 2021: https://www.cdc.gov/mmwr/preview/mmwrhtml/mm5518a2.htm.

22. Popping S, Bade D, Boucher C, et al.: The global campaign to eliminate HBV and HCV infection: International Viral Hepatitis Elimination Meeting and core indicators for development towards the 2030 elimination goals. J Virus Erad. 2019, 5:60-66. 10.1016/\$2055-6640(20)30281-8

23. World Health Organization: Global health sector strategy on viral hepatitis 2016-2021. Towards ending viral hepatitis. WHO, Geneva, Switzerland; 2016. https://apps.who.int/iris/bitstream/handle/10665/246177/WHOHIV-2016.06-eng.pdf? sequence=1 \&isAllowed=y

24. Dubin PH, Glaser FB: Knowledge gaps about hepatitis C prognosis and treatment among nongastroenterologists and medical students. Practical Gastro. 2015, XXXIX:50-55.

25. Shehab TM, Sonnad SS, Lok AS: Management of hepatitis C patients by primary care physicians in the USA: results of a national survey. J Viral Hepat. 2001, 8:377-83. 10.1046/j.1365-2893.2001.00310.x

26. Shehab TM, Sonnad SS, Jeffries M, Gunaratnum N, Lok AS: Current practice patterns of primary care 


\section{Cureus}

physicians in the management of patients with hepatitis C. Hepatology. 1999, 30:794-800.

10.1002/hep.510300328

27. Wu CA, Lin SY, So SK, Chang ET: Hepatitis B and liver cancer knowledge and preventive practices among Asian Americans in the San Francisco Bay Area, California . Asian Pac J Cancer Prev. 2007, 8:127-34. 